\title{
РАЗВИТИЕ МЕЛИОРАЦИИ НА ПРИНЦИПАХ ГОСУДАРСТВЕННО-ЧАСТНОГО ПАРТНЕРСТВА
}

\section{(c) 2019 Хаирбеков Алихан Уружалиевич}

кандидат экономических наук, ведущий научный сотрудник отдела исследования ценовых

и финансово-кредитных отношений

АПК ФГБНУ ФНЦ ВНИИЭСХ, Россия, Москва

E-mail: 156237@gmail.com

В статье рассмотрены вопросы развития мелиорации с применением механизма государственночастного партнерства в агропромышленном производстве, представлены варианты, предусматривающие взаимодействие государства и частного бизнеса, начиная с проблем восстановления гидротехнических сооружений мелиорации и заканчивая вопросами эффективного использования имеющихся земельных ресурсов. Определены направления построения рациональной системы развития мелиорации в контексте с Федеральной целевой программой «Развития мелиорации земель сельскохозяйственного назначения России на 2014-2020 гг.

Ключевые слова: государственно-частное партнерство, инвестирование, инвестиционный проект, мелиорация, сельское хозяйство

Введение. Важнейшим условием обеспечения продовольственной безопасности страны является устойчивое развитие агропромышленного производства, которое возможно лишь при эффективном использовании сельскохозяйственных угодий и минимальной зависимости их продуктивности от климатических условий. Поэтому одним из направлений ведения сельского хозяйства должна стать комплексная мелиорация земель, включающая гидромелиорацию, а также другие мелиоративные мероприятия в сочетании с прогрессивной технологией, использованием высокопродуктивных сельскохозяйственных культур, удобрений и средств защиты растений.

Аграрное производство России осуществляется в неблагоприятных для него природноклиматических условиях, где сосредоточена большая часть всех посевов сельскохозяйственных культур, в том числе зерновых. Для получения стабильного урожая зерна сумма атмосферных осадков должна составлять не менее 700 мм в год. А в России в таких условиях располагается всего около 1\% пашни (в США - 60\%). В США примерно $70 \%$ сельскохозяйственных земель имеет безморозный период 170 дней, у нас таких земель примерно 15\%. В целом биоклиматические условиях для развития сельского хозяйства в нашей стране хуже, чем в США, примерно в 2,4 раза $[1$, с. 21$]$. В этой связи необходимо постоянное подержание почвенного плодородия сельскохозяйственных угодий, на основе проведения культуртехнических работ и мелиорации, а также вовлечение в сельскохозяйственное производство неиспользуемых земель сельскохозяйственного назначения.

В Большой советской энциклопедии мелиорация объясняется как, «... совокупность организационно-хозяйственных и технических мероприятий, направленных на коренное улучшение земель» [2], как важнейшее условие интенсификации сельскохозяйственного производства.

Следует отметить, что в процессе проведения скоропалительных реформ в аграрной сфере государство, практически отказалось от финансирования строительства мелиоративных систем. В структуре субсидий из федерального бюджета в статье расходов исчезла строчка «строительство мелиоративных систем», осталась лишь косвенная поддержка. В результате, если в 1990 г. в эксплуатацию было введено 105 тыс. га орошаемых земель и 162 тыс. осушенных, то в 2000 г. соответственно 5 тыс. и 14 тыс., а в 2010 г. 2,0 тыс. га орошаемых и 2,5 тыс. осушенных земель [3, с. 53]. В настоящее время с целью развития мелиорации земель разработана и действует федеральная целевая программа «Развитие мелиорации земель сельскохозяйственного назначения России на 2014-2020 гг.» (ФЦП «Мелиорация») [5].

По данным Минсельхоза России в пользо- 
вании сельхозтоваропроизводителей находится 9,45 млн. га мелиорированных земель, в том числе 4,67 млн. га орошаемых и 4,78 млн. га осушенных земель, которые занимают около 8\% от площади пахотных угодий. Однако для выращивания сельскохозяйственных культур используется 7,1 млн. га мелиорированных земель, или $75 \%$ общей площади, в том числе 3,88 орошаемых и 3,22 осушенных [5].

Несмотря на функционирование ФЦП «Мелиорация» наблюдается значительное сокращение показателя вовлечения в оборот выбывших (неиспользуемых) сельскохозяйственных угодий РФ за счет проведения культуртехнических работ в 2014-2017 гг. на 130\% или в 1,3 раза.

Как видно из таблицы 1 , в большинстве федеральных округов данный показатель имеет устойчивую тенденцию к снижению. Даже если учесть некоторое увеличение по СевероЗападному, Северо-Кавказскому и Дальневосточном федеральным округам, то это малая часть от 2-х млн. га земли, которые находятся в пользовании сельхозтоваропроизводителей и не используются по назначению.

Основным источником финансирования
ФЦП «Мелиорация» за 2014-2017 гг. выступает Федеральный бюджет РФ и средства внебюджетных источников. За анализируемый период финансирование увеличилось на 18\%, причем из Федерального бюджета в 2017 г. было выделено на 44,3\% больше, чем в 2014 г., по другим источникам финансирования значительных изменений нет. Примечательным является тот факт, что в 2017 г. при увеличении финансирования ФЦП «Мелиорация», ее плановые и фактические показатели значительно сократились по сравнению с 2015 г. хотя условия экономической политики не претерпели существенных различий.

Если провести краткий экскурс программ развития и восстановления сельскохозяйственных угодий РФ, то, по мнению А.Г. Зельднера, наблюдаются следующие тенденции развития:

- Федеральная целевая программа «Плодородие». На реализацию программы в 19922000 гг. из плановых 243 млрд. руб. было реально выделено 34 млрд. руб. (14\%);

- Федеральная целевая программа «Сохранение и восстановление плодородия почв земель сельскохозяйственного назначения и агроландшафтов как национального достояния

Таблица 1. Вовлечение в оборот выбывших (неиспользуемых) сельскохозяйственных угодий за счет проведения культуртехнических работ по ФЦП «Мелиорация», тыс. га

\begin{tabular}{|l|c|c|c|c|c|}
\hline \multicolumn{1}{|c|}{ Федеральные округа } & 2014 г. & 2015 г. & 2016 г. & 2017 г. & $\begin{array}{c}2017 \text { г. к } \\
2014 \text { г.,\% }\end{array}$ \\
\hline Центральный ФО & 117,9 & 106,7 & 80,5 & 14,9 & 12,64 \\
\hline Северо-Западный ФО & 12 & 12 & 21,2 & 37,3 & 310,83 \\
\hline Южный ФО & & 1 & 1,5 & 1,5 & - \\
\hline Северо-Кавказский ФО & 1,9 & 2,5 & 1,9 & 2,4 & 126,32 \\
\hline Приволжский ФО & 21,7 & 30,4 & 9,7 & 2,2 & 10,14 \\
\hline Уральский ФО & 2,5 & 3 & & & - \\
\hline Сибирский ФО & 17,7 & 27,2 & 24,1 & 9,9 & 55,93 \\
\hline Дальневосточный ФО & 3,5 & 3 & 3,8 & 5,7 & 162,86 \\
\hline
\end{tabular}

Источник: Агропромышленный комплекс России в 2017 г. [4]

Таблица 2. Ресурсное обеспечение мероприятий ФЦП «Мелиорация», млн. руб.

\begin{tabular}{|l|c|c|c|c|c|}
\hline \multicolumn{1}{|c|}{ Наименование } & 2014 г. & 2015 г. & 2016 г. & 2017 г. & $\begin{array}{c}2017 \text { г. к } \\
2014 \text { г.,\% }\end{array}$ \\
\hline \multicolumn{1}{|c|}{ Всего } & 20401,8 & 17477,0 & 16006,0 & 23994,6 & 117,61 \\
\hline В том числе средства Федерального бюджета & 7724,1 & 7835,0 & 7338,5 & 11149,5 & 144,35 \\
\hline $\begin{array}{l}\text { средства бюджетов субъектов Российской } \\
\text { Федерации и местных бюджетов }\end{array}$ & 2086,2 & 1721,0 & 1077,0 & 2116,3 & 101,44 \\
\hline средства внебюджетных источников & 10591,5 & 7921,0 & 7591,0 & 10728,8 & 101,30 \\
\hline
\end{tabular}

Источник: Национальный доклад о ходе реализации Госпрограммы 
России на 2006-2010 гг.», продлена до 2013 г. На реализацию программы было выделено 370,9 млрд. руб. (федеральный бюджет - 17,2\%, региональные бюджеты - 22,0\%, внебюджетные источники - 60,8\%);

- Федеральная целевая программа «Развитие мелиорации земель сельскохозяйственного назначения России на 2014-2020 гг.». На реализацию программы выделено 185 млрд. руб.

Как показывает опыт реализации Федеральных целевых программ развития мелиорации за период 1992-2017 гг., даже при положительной тенденции сложно определить эффективность этих мероприятий.

Одним из показателей определения эффективности программ развития мелиорации является использование свежей воды на орошение и сельскохозяйственное водоснабжение, который показан на рисунке 1 . Несмотря на реализацию 3-х программ развития мелиорации, за период 1990-2017 гг. количество использования воды на орошение сократилось на 13,4 млрд. $\mathrm{m}^{3}$. Это говорит о недостаточном финансировании программ развития мелиорации и неэффективном использовании выделяемых ресурсов.

В результате изучения и обобщения отечественного и зарубежного опыта можно сделать вывод, что наиболее дееспособным и эффективным институтом является государственночастное партнерство (ГЧП) практически во всех сферах экономики. По сути, это консолидация усилий государства и частного бизнеса с целью привлечения инвестиций для реализации крупных и социально-значимых инвестиционных проектов.

Федеральный закон «O государственночастном партнерстве, муниципально-частном партнерстве в Российской Федерации» от 13.07.2015 г. № 224, гласит, что «Государственночастное партнерство, муниципально-частное партнерство - юридически оформленное на определенный срок и основанное на объединении ресурсов, распределении рисков сотрудничество публичного партнера, с одной стороны, и частного партнера, с другой стороны, которое осуществляется на основании соглашения о государственно-частном партнерстве, соглашения о муниципально-частном партнерстве, заключенных в соответствии с настоящим Федеральным законом в целях привлечения в экономику частных инвестиций, обеспечения органами государственной власти и органами местного самоуправления доступности товаров, работ, услуг и повышения их качества» [7]. Стало быть, Закон говорит о необходимости привлечения в экономику частных инвестиций с целью реализации крупных инфраструктурных объектов, к которым относится и мелиорация.

Варнавский В.Г. считает, что ГЧП - это «система сложившихся к настоящему времени партнерских отношений государства с частным сектором является одним из проявлений смешанной экономики. В рамках теории смешанной экономики государство посредством ГЧП отказывается от неэффективных форм ведения хозяйства, перекладывая функции управления принадлежащей ему собственностью на частный сектор. Бизнес, в свою очередь, пользуясь

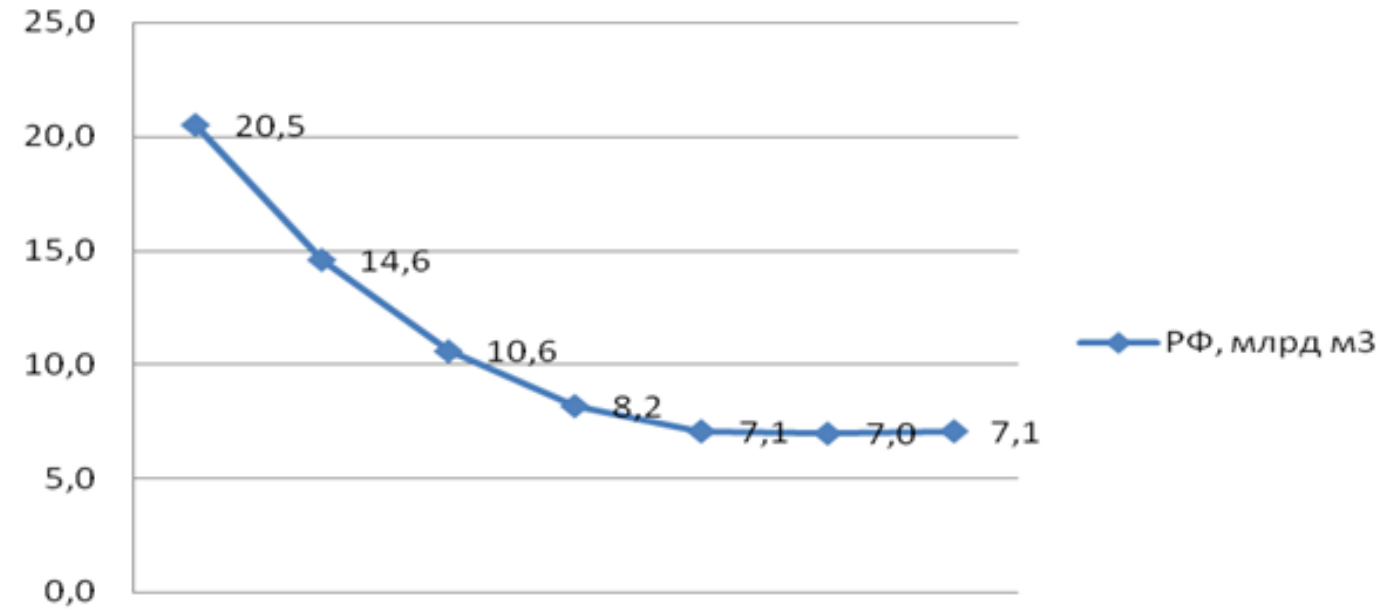

1990 r. 1995 r. 2000 r. 2010 r. 2015 r. 2016 r. 2017 r.

Рисунок 1. Использование свежей воды на орошение и сельскохозяйственное водоснабжение в РФ, млрд. $\mathbf{M}^{3}$ [6] 
государственными гарантиями, привносит в производство организационный опыт, знания, ноу-хау, осуществляет инвестиции, минимизирует риски предпринимательской деятельности» [8].

В.3. Мазлоев, О.И. Хайрулина в своей статье приводят следующее: «В узкой трактовке ГЧП характеризуется следующими основными признаками:

- стороны партнерства представляют интересы как государственного и частного сектора экономики;

- взаимоотношения сторон государственночастного партнерства должны быть юридически закреплены в официальных документах (договорах, контрактах);

- экономические отношения сторон ГЧП должны быть равноправны;

- стороны государственно-частного партнерства должны объединять вклады для реализации общих интересов;

- совместное распределение доходов, расходов и рисков, а также участвовать в использовании полученных результатов.

В широком понимании ГЧП - это:

- специальные меры налоговой, кредитной, антимонопольной, внешнеторговой политики;

- прямое государственное финансирование проектов [9].

Зельднер А.Г. в своей монографии отмечает «ГЧП - это не только, как считают многие экономисты, альянс между государством и бизнесом в целях реализации общественно значимых проектов. К рассмотрению сущности ГЧП необходимо подходить с нескольких позиций. Во-первых, это система социально-экономических отношений между государством и бизнесом, направленная на обеспечение устойчивого развития. Во-вторых, это конкретные проекты, совместно реализуемые государством и бизнесом. ГЧП это союз между властью, бизнесом и институтами гражданского общества, это механизм привлечения инвестиционных ресурсов для обеспечения воспроизводственного процесса. Это процесс, формирующий толерантную среду, и основа для становления социализации общественных отношений на базе смешанной экономики. ГЧП имманентно сельскому хозяйству, ибо во всех развитых странах это направление поддерживается государством за счет бюджета при реализации крупных инфраструктурных проектов, развития социальной и инновацион- ной сфер, налоговых, таможенных и кредитных льгот» [3].

Партнерство государства с частным сектором является ключевым компонентом инвестиционной политики РФ, поскольку, при правильной организации, оно обеспечивает получение большего эффекта от вложенных средств. При этом приоритетным направлением использования возможностей государственно-частного партнерства должно быть агропромышленное производство ввиду его важности и значимости, как для нашей страны, так и для увеличения экспорта и агропродовольствия, а следовательно, реальная возможность пополнения доходной части бюджета России. Для активизации ГЧП в мелиорации, и в особенности для частного инвестора, необходимо обеспечить инвестиционную привлекательность данного направления. То есть, государство должно воздействовать на условия взаимодействия с помощью организационных мер, нормативно-правовой базы и финансово-экономических инструментов таким образом, чтобы снизить риски инвестора и обеспечить приток инвестиционно-финансовых ресурсов в мелиорацию.

В частности в виде организационноэкономической модели можно предложить партнерство государства и частного аграрного бизнеса в вопросе восстановлении и улучшении гидротехнических систем мелиорации (Рис. 2). В данной модели ГЧП в роли партнеров выступают государственные органы и частные компании, которые за счет собственных источников и инвестиционных ресурсов могут создавать, восстанавливать гидротехнические сооружения мелиорации, на тендерной основе.

Механизм ГЧП восстановления и использования мелиорации может быть представлен в нескольких вариациях.

1. Частные компании на тендерной основе создают, либо восстанавливают, гидротехнические мелиоративные системы, государство предоставляет пользование этими системами данным компаниям на время компенсации (окупаемости) затрат с долей доходности и предоставлением налоговых преференций. В свою очередь частные компании могут взаимодействовать со всеми субъектами сельскохозяйственного производства данного региона обеспечивая их услугами водоснабжения и орошения на платной основе, обеспечивая таким образом доходность инвесторов. 


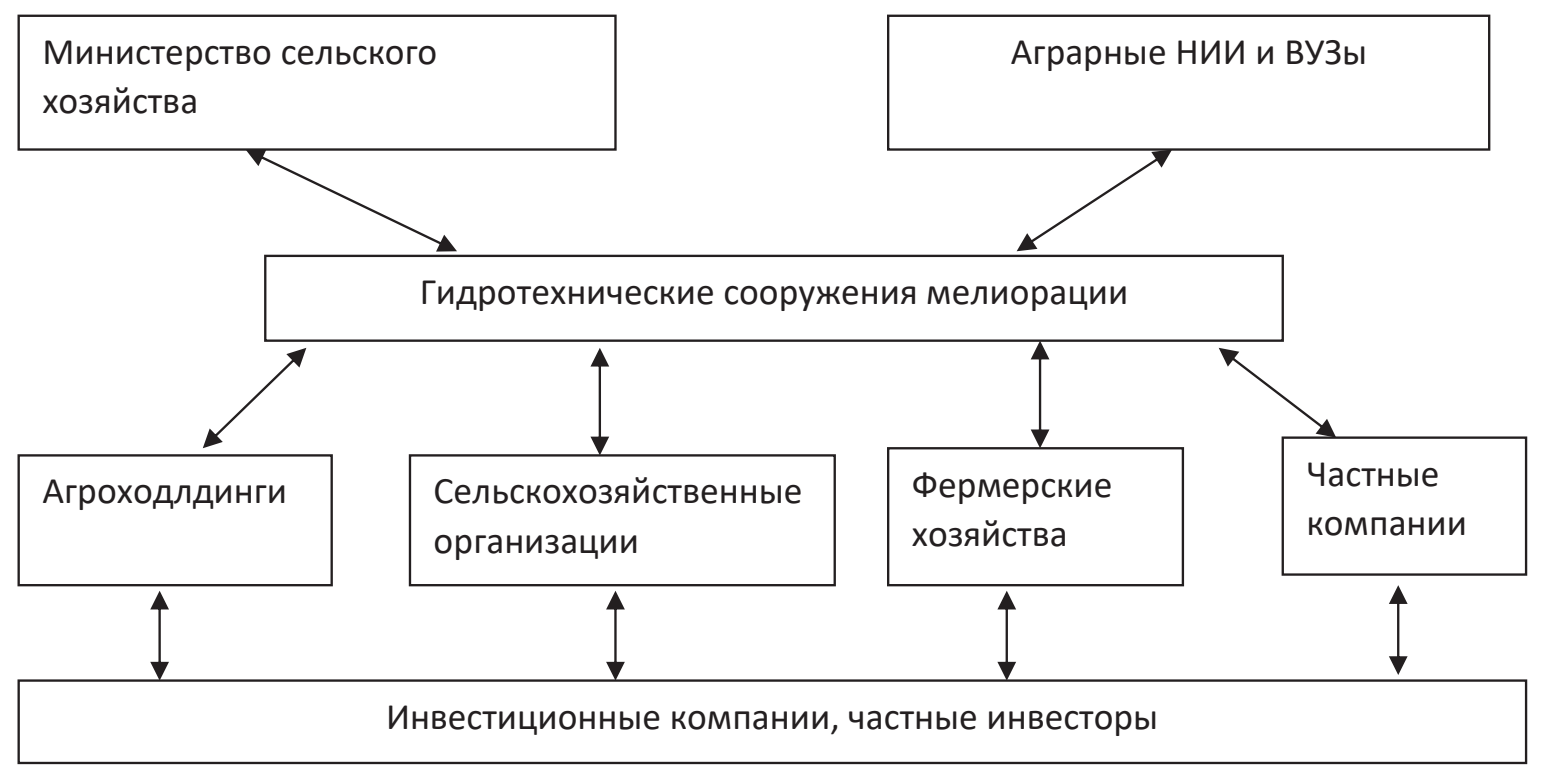

Рисунок 2. Модель государственно-частного партнерства создания и использования гидротехнических сооружений мелиорации

2. В роли партнеров государства могут выступить хозяйствующие субъекты аграрной отрасли, которые за счет собственных средств и средств инвесторов могут восстановить и создать гидротехнические мелиоративные системы. На условиях партнерства государство может предоставить во временное пользование сельхозтоваропроизводителям гидротехнические мелиоративные системы на время окупаемости затрат, с учетом налоговых преференций.

3. Государство и частный бизнес могут создавать институты партнерства по поводу мелиорации земель в части химизации, агролесомелиорации, других видов восстановления почв и выбывших из оборота сельскохозяйственных угодий. В данной модели государство может предоставить эти земли участникам партнерства на время возмещения затрат.

4. Немаловажным инструментом ГЧП выступает лизинг, где АО «Росагролизинг», как представитель государства, на льготных условиях может предоставить сельхотоваропроизводителям дождевальные и оросительные системы с применением налоговых преференций на время проведения мелиоративных работ.

Выгода государства в таких взаимоотношениях состоит в эффективном менеджменте, целевом расходовании бюджетных средств, создании рабочих мест и функционировании механизма региональной гидротехнической мелиоративной системы. Выгода частного бизнеса заключается в гарантированной доходности выполняемого тендерного договора, с последующим сопровождением гидротехнической системы мелиорации на основе рыночного механизма взаимодействия с инвесторами и субъектами сельскохозяйственного производства, а также льготные преференции по налогам и лизинговым сделкам.

\section{Библиографический список}

1. Боев В.P., Зельднер А.Г. Экономические рычаги ускорения научно-технического прогресса. М.: Агропроиздат, 1988.- 200 с.

2. Большая советская энциклопедия. [Электронный ресурc]. URL: http://bse.sci-lib.com/article075318.html

3. Зельднер А.Г. Экономический механизм обеспечения продовольственной безопасности в условиях инвестиционных ограничений: опыт и проблемы [Текст] / А.Г. Зельднер.- М.: Вузовский учебник: ИНФРА-М, 2018.-160c.

4. Агропромышленный комплекс России в 2017 году. [Электронный ресурс] - URL: https://rosinformagrotech. $\mathrm{ru} /$ 
5. Национальный доклад о ходе и результатах реализации в 2017 году государственной программы развития сельского хозяйства и регулирования рынков сельскохозяйственной продукции, сырья и продовольствия на 2013-2020 годы. [Электронный ресурс] - URL: https://rosinformagrotech.ru/

6. Российский статистический ежегодник. 2018: Стат. сб./ Росстат.-М., 2018-694 с.

7. Федеральный закон «О государственно-частном партнерстве, муниципально-частном партнерстве в Российской Федерации и внесении изменений в отдельные законодательные акты Российской Федерации» от 13.07.2015 N224-Ф3

8. Варнавский В.Г. Управление государственно-частными партнерствами за рубежом // Вопросы государственного и муниципального управления. 2012. № 2. С. 134-147

9. Мазлоев В.З., Хайрулина О.И. Государственно-частное партнерство по технической модернизации мясного скотоводства // Экономика сельскохозяйственных и перерабатывающих предприятий. 2016. № 9. С. 28 -33.

10. Кулов А.Р. Государственно-частное партнерство в системе инввестирвоания в социальную инфраструктуру сельских территорий // Экономика сельского хозяйства России. 2018. № 5. С. 82-91

11. Хаирбеков А.У., Кибиров Х.Г. Инвестирование в агропромышленное производсво на принципах государственно-частного партнерства // Теория и практика мировой науки. 2018. № 2. С. 8-12 